\title{
Discussion on the Development of Artificial Intelligence in Taxation
}

\author{
Zhuowen Huang \\ Nanfang College of Sun Yat-sen University, Guangzhou, China \\ Email: happyhzw@hotmail.com
}

How to cite this paper: Huang, Z.W. (2018) Discussion on the Development of Artificial Intelligence in Taxation. American Journal of Industrial and Business Management, 8, 1817-1824.

https://doi.org/10.4236/ajibm.2018.88123

Received: July 30, 2018

Accepted: August 25, 2018

Published: August 28, 2018

Copyright $\odot 2018$ by author and Scientific Research Publishing Inc. This work is licensed under the Creative Commons Attribution International License (CC BY 4.0).

http://creativecommons.org/licenses/by/4.0/

\begin{abstract}
With the development of AI technology, a new forecasting and statistical model for tax auditing has been created. In recent years, thanks to breakthroughs in AI research, tax professionals have gained new analytical and statistical tools, providing convenience and improving efficiency. These tools have formed the basis for systematic frameworks that avoid the disorder and complexity of data processing and analysis in Excel spreadsheets. Additionally, AI provides simulated tax risks, which can help more complex human judgments to be made. AI can also aid detection of fraud, contributing to its supervision and monitoring by government. The development of AI continues, and its deployment has certain limits and risks that must be recognized.
\end{abstract}

\section{Keywords}

Artificial Intelligence (AI), Taxation, Supervision

\section{Introduction}

The structure of this paper is organized by five parts. The first part describes the concept of AI and the AI background, and then the paper analyzes how AI can be applied in taxation, next, the paper focus on AI application of taxation in China and in globally. The last part summarizes the obstacles of using AI in practice, the prospects of AI in China, and suggestion. The main contribution of this paper is that it gives a relatively clear picture about the problems of using AI in taxation in China. The main limitation of this paper is to present facts of AI development in China and pinpoint potentials of using AI in taxation in China. It presents the reality of AI being developed in China without substantial researches and data analysis.

\subsection{Artificial Intelligence Concept}

Artificial intelligence (AI) is a broad term that refers to techniques making ma- 
chines "intelligent". AI research and application utilize automation to enhance or replicate human intelligence to improve the analysis and decision-making capabilities of machines. AI provides managers with unprecedented tools to ease the complexity of decision-making, serving as a catalyst for internal structural transformation in various industries. It also allows complicated and time-consuming tasks to be completed more effectively and efficiently.

\subsection{Development of Artificial Intelligence in Taxation}

Pascal A. Bizarro and Margaret Dorian (2017) pointed out that artificial intelligence (AI) was born in 1948, when William Gray Walter created two small robots, named "Elmer" and "Elsie", that were able to recognize and respond to stimuli while encountering obstacles [1]. Two years later, Alan Turing (1950) proposed that a machine could transmit information, communicate, and possess thinking capabilities indistinguishable from those of humans [2]. In 1956, the Dartmouth workshop proposed the term "artificial intelligence", marking the birth of AI as a discipline [3]. Since then, the AI phenomenon has received considerable attention in various fields. According to the $41^{\text {st }}$ "Statistical Report on Internet Development in China" in 2017, published by China Internet Network Information Center (CNNIC), there are $2542 \mathrm{AI}$ companies globally, including 1078 in the United States (accounting for 42.4\%) and 592 in China (23.3\%) [4]. Familiar AI products include Apple's Siri, self-driven cars, and virtual reality head-mounted displays. In the field of taxation, this ever-developing technology can enhance the effectiveness of automated tax auditing and decision-making, and play an essential role in supervision and monitoring by the government.

\section{How Is AI Applied in Taxation?}

To understand how AI is applied in taxation, Cas Milner and Bjarne Berg (2017) believe that AI's role in taxation is like a software that can automatically adapt to the input of different content and make judgments without specific instructions [5]. While AI robots acting as tax accountants is currently believed to be unlikely, they can perform various roles, such as assisting tax auditors in detecting errors, classifying accounts and transactions, assessing tax audit risks, and increasingly propose favorable tax strategies within the framework of complex global laws. There are many prospects for applying AI in taxation. It is instructive to consider some of the most successful accounting firms. Below, we briefly discuss their application and development in AI.

According to PwC's official website, the combination of tax accounting and AI, integrating the accounting system of the entire enterprise is similar to an ecosystem. The following illustration depicts an automated system that provides an integrated tool that improves efficiency, enhances data quality, and adapts to ever-changing risk environments through constant information flow between three parts, as shown in Figure 1 [6]:

KPMG's official website recently reported the launch of "Tax Service," an 


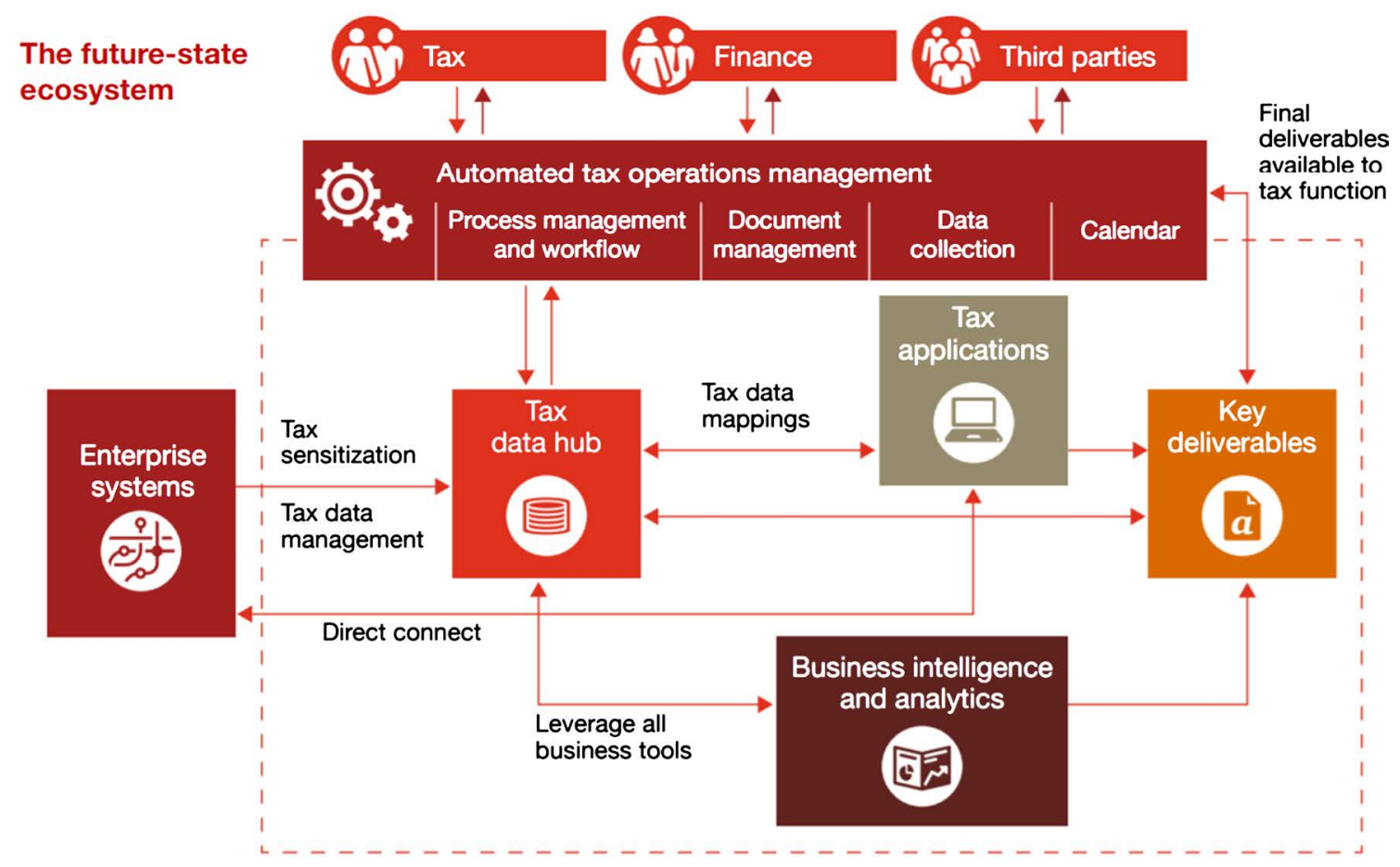

Figure 1. The future-state ecosystem.

intelligence tax product that assists Chinese companies to solve automated tax compliance problems. In China's tax system, policy changes are frequent and complex. If the tax information or the review process is omitted without the help of AI, serious tax risks and consequences could result, which can be avoided by using AI that can integrate and conform to the current policy to speed up tax declaration process. In addition, KPMG's “Tax Service” product can perform automatic preparation of VAT and corporate income tax returns, as well as local additional tax calculation tables, trend analysis, and the timely detection of potential errors, risks, or abnormal conditions [7].

\section{The Development of AI in China}

In China, with the development of AI, more standardized policies have emerged, like the "New Generation Artificial Intelligence Development Plan." AI is a new and strategic technology that leads the future, enhances the country's competitiveness, and maintains national security, undoubtedly a positive influence on the development of AI.

China has begun to promote AI in taxation. In Guangdong, a tax robot has been introduced. It has completed a total of 12,000 times similar to human-computer transections in reality and has handled regular business for 660 individual, industrial, and commercial taxpayers. Its contribution accounts for $54.91 \%$ of regular business, thereby halving the workload for, and reducing the burden on, civil servants [8]. In the Dianbai District of Maoming City, Guangdong Province, the Taxation Bureau Office has introduced China's first "face-to-face tax" intelligent robot. It can collect taxpayer information, such as 
their face photo, ID card, and contact number through scanners during process of date submission; once this information is authenticated, the taxpayer's identity can be verified, which improves efficiency [8]. Meanwhile, the "taxation bureau of Shanghai Fengxian District" operates the "Fengxian Tax" WeChat public forum and mobile phone tax software, enabling taxpayers to check tax-related information concerning, for example, policy updates, tax processes, and information disclosure [8]. In the Shijingshan District National Taxation Bureau of Beijing, taxpayers can consult the Lingyun robot. It listens to questions posed by taxpayers, processes the information, and responds to their queries, making judgments on the problems they present. The development of AI "reply by voice" is already very advanced in this field, drawing on several advanced technologies. such as: Lingyun speech recognition which recognizes spoken questions and answers and semantic understanding which recognizes meaning of spoken questions and answers. With continuing adjustments, these technologies will be near perfection [8].

\section{Global Developments}

Globally, an increasing number of countries are developing and diversely applying AI technology. With the rapid development of tax technology, the demand for AI in taxation is also growing. There are many reasons for this. For multinational companies, integrating data through AI will maximize their ability to collect and analyze data, and help them adapt to changing policies on tax compliance processes. Moreover, automation will greatly increase the transparency of tax data, helping multinationals to satisfy government demands for accurate tax reporting, in detail and in real time, while also improving the development of government regulation.

As a result, AI is highly valued. Additionally, AI has been more prevalent due to government promotion. Through deployment of AI, the collection and organization of tax data becomes more systematic and transparent. This helps to curtail unreasonable tax avoidance by international companies, eliminate illegal tax evasion, help to curb multinational companies' profit transfers and tax base erosion, the reason why there was the participation of more than 100 countries in the Organization for Economic Cooperation and Development (OECD/G20) and Base Erosion and Profit Shifting (BEPS) project [9]. Applying AI to streamline tax data by government increases efficiency and compliance with current policies on tax reporting and reasonable tax avoidance. Furthermore, data collected through AI can be used to establish mathematical models, analyze the tax trends and indicators of various enterprises, and adjust various tax policies. For tax administration departments, processing tax data through AI accelerates the identification and analysis of the enterprise's tax problems, which may include unreasonable tax avoidance or tax evasion. Consequently, such problems can be immediately contained and enterprises can maximize their legitimate income. AI enhances the systematic processing and transparency of tax data, which increas- 
es the intensity of government supervision and motivates the ongoing development of AI.

\section{Conclusions}

To summarize, there are three points that should be noted.

\subsection{The Obstacles of Using AI in Practice}

During the process of information collection for this paper, it is found that the application of AI in taxation is not prevalent in China. One reason is that Chinese tax law is versatile and changes frequently, requiring AI systems to be updated correspondently with concurrent policy revisions. Addition and deduction rules can be good examples as to why AI systems need to be updated constantly in order to accommodate the rapid policy changes. For example, the previous deduction rate for the $R \& D$ expenses of general enterprises is $50 \%$, which had been updated to $75 \%$ in the AI system due to the policy changes made in the early 2017 in order to be enforced between January 1, 2017 and December 31, 2019 [10]. The policy is constantly updated and changed so that AI applications in the tax system must be updated and changed simultaneously. As a result, AI system needs adjustments in order to produce accurate tax audit report. Keeping the system up to date with new policies will undoubtedly make the AI system more acceptable and prevalent. However, at present, AI is still developing, and the AI system is not able to update itself since manual adjustments are needed. In turns of data input, integration and tax reports preparation, AI system in taxation can be still more advanced.

Under the "Notice of the State Administration of Taxation on Regulating Tax Exemption for Compulsory Certification Services" (Tax General Letter [2014] No. 220), not all Chinese enterprises are required to issue tax audit reports [11]. For those exempt, AI does not seem to be needed in the data process, which can reduce the costs of researching and developing tax-based AI systems. It is certainly questionable whether cost reductions can be achieved given the need to frequently implement updates as law and policy changes. Is it even possible to reduce costs without using AI systems in taxation? The validity of this assumption requires in-depth investigation. It should also be noted that AI in China's taxation is at an immature development stage. How long it might take to mature is difficult to accurately predict.

\subsection{The Prospects of AI in China}

However, we cannot deny the opportunities and advantages brought by AI. The above analysis clearly demonstrates the great convenience it offers. In the context of large amount of data, and with the need to handle complex data or integrate systems, AI can be more accurate and efficient.

\subsubsection{Structure Change}

On June 15, 2018, China's national and local taxes were merged into one, which 
means that taxation process will be streamlined, therefore operating more quickly [12]. In 2015, the China Office and the State Council issued the "Reform Plan for the National Tax and Local Tax Collection and Management System," clarifying the "cooperation" between national and local tax authorities. In many areas, national and local tax authorities began to jointly manage taxes. For example, through the collaboration, the Tax Bureau Joint Office was established, providing services to improve taxpayers' experience and the efficiency of tax authorities [13]. For example, now China's tax bureaus all share a system promoting extensive cooperation and integration between the national and local authorities. Solid foundations were thereby laid for the merger. Consequently, we also urgently need AI systems to help companies more quickly generate tax reports and submit them to the tax bureau in accordance with the trend of systematic development and transparency.

\subsubsection{The Potential in International Reporting}

Despite the rapid development of taxation in AI, global governments are still facing challenges as to data comparability and verifiability due to the fact that there is no universally accepted tax system. Is it possible to make the tax data of multinational corporations more transparent and universal so that accountability of international tax reporting can be improved? For instance, data and income of a foreign enterprise owned by a Chinese resident abroad can be quickly intercepted by the Chinese tax bureau to avoid tax avoidance and evasion. Additionally, AI system can play a supervisory role in reporting whether the domestic and foreign incomes are reported truthfully.

\subsubsection{An Unstoppable Trend}

Indeed, AI in China is still not prevalent due to rapid policies changes without sufficient updates and the high costs of integration of AI to current tax systems. Nonetheless, the development of AI is an unstoppable trend, and will become more mature and standardized in the future.

1) In China, government is accelerating the reform of various taxation systems; moreover, the long-term management philosophy and methods of the Chinese tax authorities are undergoing major changes.

2) In global, the "Statement on Algorithmic Transparency and Accountability" outlines seven principles, which helps the development and application of AI in taxation with a clearer policy norm and increased usability [14].

3) Finally, in China, the State Council's notice on the issuance of "a new generation of AI development plan" [2017] No. 35 by the State Council indeed provide support to AI policy and standardization [15].

\subsection{Suggestion}

At present, it is critical for both government and companies to establish and utilize the AI in taxation. The government should seize this opportunity to fully tap the huge value of the hidden potential of using AI in taxation. AI, with tre- 
mendous data and analytical capability, is an invaluable tool for tax authorities, helping them to better understand clients and to simulate future business scenarios. Corporations can use AI to develop advanced tools for monitoring behaviors and activities in real time and analysis. AI systems can adapt to ever-changing risk environments, helping corporations to continuously improve their monitoring capabilities and transparency with regard to regulatory compliance and corporate governance. In addition, AI can be developed from a warning system into a precognition system to help companies avoid risks through tax analysis and predictions. For example, AI can be used to more accurately predict the probability of a certain enterprise defaulting on loans or overdue payments. Thus, the companies need to fully use AI in taxation, which would keep them more competitive in the future.

\section{Conflicts of Interest}

The author declares no conflicts of interest regarding the publication of this paper.

\section{References}

[1] Bizarro, P.A. and Dorian, M. (2017) Artificial Intelligence: The Future of Auditing. Internal Auditing, 5, 21-26.

[2] Turing, A.M. (1995) Computing Machinery and Intelligence. Computation \& Intelligence. American Association for Artificial Intelligence, Palo Alto, 44-53.

[3] Moor, J. (2006) The Dartmouth College Artificial Intelligence Conference: The Next Fifty Years. Ai Magazine, 27, 87-91.

[4] CNNIC (2018) The 41st “Statistical Report on the Development of China's Internet. http://www.cnnic.net.cn/hlwfzyj/hlwxzbg/hlwtjbg/201803/t20180305 70249.htm

[5] Milner, C. and Berg, B. Tax Analytics-Artificial Intelligence and Machine Learning-Level 5.

https://www.pwc.com/us/en/services/tax/tax-innovation/artificial-intelligence-andmachine-learning.html

[6] PWC (2015) Unlocking the Power of Data and Analytics. https://www.pwc.com/gx/en/tax/publications/assets/PwC TFoF DataAnalytics glo bal nov2015.pdf.

[7] KPMG. KPMG China's Highly Automated Tax Compliance Solution. https://home.kpmg.com/cn/en/home/services/tax/tax-technology/tax-compliance.h $\underline{\mathrm{tml}}$

[8] Ding, F. (2017) “AI+ Tax" Will Become the "Black Technology” of the Tax System. http://www.shui5.cn/article/ef/113244.html

[9] Viglione, J. and Deputy, D. (2017) Your Tax Data Is Ripe for Artificial Intelligence. Are You Prepared? AI Is Still Evolving, but Machine Learning Is Already Here. Tax Executive. https://www.highbeam.com/doc/1G1-510480668.html

[10] Zhonghui (2018) Will It Be a High-Tech Enterprise to Enjoy 75\% of the Research and Development Expenses? http://www.shui5.cn/article/b1/118937.html

[11] Shuiwu (2014) Notice of the State Administration of Taxation on Regulating Tax Exemption for Compulsory Certification Services.

http://www.shui5.cn/article/de/72010.html 
[12] Shuang, D. (2018) Research on Tax Service Optimization Based on the Combination of State and Land Taxes. Tax, No. 16, 27.

[13] Wen, C.X., Liu, J.Y., Yu, J.Y. and Wang, P., et al. (2015) Speeding up the Reform of Tax Collection and Management System-Review of the Reform Plan of Deepening the National Tax and Local Tax Collection and Management System. China Tax, No. 12, 15-16.

[14] Garfinkel, S., Matthews, J., Shapiro, S.S., et al. (2017) Toward Algorithmic Transparency and Accountability. Communications of the ACM, 60, 5. https://doi.org/10.1145/3125780

[15] State Council (2017) Notice of a New Generation of Artificial Intelligence Development Planning. http://www.gov.cn/zhengce/content/2017-07/20/content 5211996.htm 